\title{
POLÍTICAS EDUCACIONAIS NA DITADURA MILITAR BRASILEIRA: ENTRE O GIZ E O CHUMBO
}

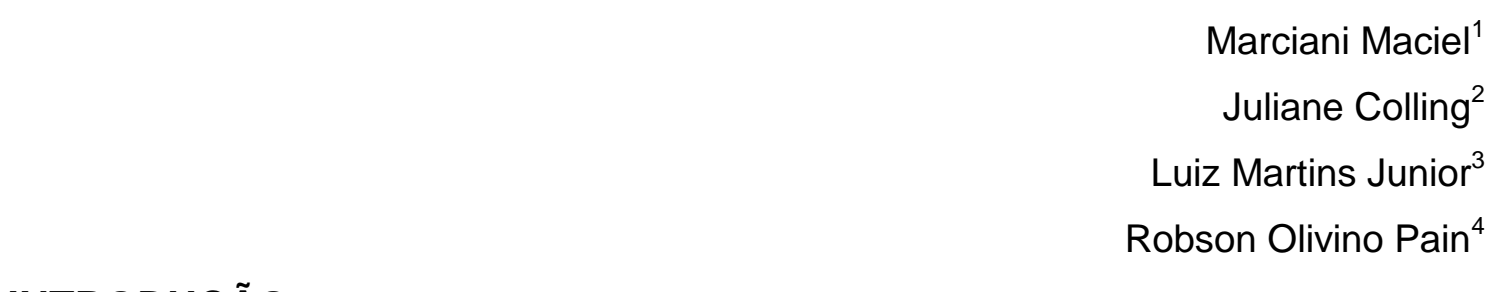

\section{INTRODUÇÃO}

Este estudo propõe uma retomada histórica o período de 1964-1985, onde a partir da consolidação do golpe instala-se a Ditadura Militar no Brasil, bem como percorrer as reformas educacionais do regime. Com o intuito de trazer átona a intencionalidade de tal era. A abordagem teórica do texto dispõe sobre dois ângulos: Inicialmente apresentaremos como o golpe se torna governo e como caracterizou-se o comando militar no Brasil, na sequência a abordagem fica por conta das políticas educacionais, as reformas nos moldes do regime, que constituiu o cenário educacional nos anos de chumbo no país.

Ao longo do tempo, em cada sociedade, os valores, ideias e regras permeiam a organização dos homens. Os homens por sua vez são seres providos de historicidade, assim sendo não pode o homem negar sua própria história. Partindo de tal premissa torna-se fundamental a necessidade de compreender como se dá o processo de constituição sociopolítica de nosso país. Sendo de fundamental importância que no processo de formação de educadores/pesquisadores estas compreensões sejam asseguradas e efetivadas por meio de estudos que lhe dêem o arcabouço teórico para tal.

A compreensão da consolidação do golpe, a forma de governo militar e as reformas educacionais, tornou-se mais do que um apanhado histórico do passado, o qual já seria justificável, mas, uma questão de autonomia pelo conhecimento.

\footnotetext{
${ }^{1}$ Universidade Federal da Fronteira Sul, marciani maciel@hotmail.com

2 Universidade Federal da Fronteira Sul, Julianecolling gti@hotmail.com

${ }^{3}$ Universidade Federal de Santa Catariana, Luizmartins.jr@hotmail.com

${ }^{4}$ Universidade Federal de Santa Catarina, robson.paim@uffs.edu.br
} 
Sobre a necessidade da contextualização histórica da era militar de 64, nunca se fez tão necessário. Em meio a um cenário político conturbado, de disputa de poder, onde um golpe a democracia do país é cogitado, aclamar a intervenção militar tornou-se moda, todavia sem conhecimento de causa.

Abordar um tema de tal impacto, sem precedentes, onde as forças armadas exerceram o comando do Brasil - a ditadura militar -, tornou-se fundamental para a compreensão do passado, para as ações do presente e para as escolhas do futuro.

\section{E O GOLPE VIRA GOVERNO}

Conforme Germano (2011, p. 34): [...] à medida que o tempo passa e nos distanciamos daqueles "anos de chumbo", a política educacional do período deva ser constantemente revista, não somente no sentido da produção de um conhecimento a respeito - que em si constitui um motivo plausível, mas, igualmente, no sentido de resistir a toda forma de autoritarismo passado e presente.

O regime militar nos fez herdeiros de um vasto legado, também no campo educacional que segue influenciando a educação no país. Como ressalta Saviani (2008, p. 295), "Faz sentido, pois, retomar a política educacional e as realizações da ditadura no Brasil, pondo em destaque aspectos que se fazem presentes, ainda hoje, na educação brasileira".

João Goulart assumiu a presidência do país através do parlamento em 1964, numa época que o Brasil passava por dificuldades econômicas, sociais e políticas (SCHWARCZ; STARLING, 2015, p. 434).

Esquerda e direita disputavam o projeto do país em 1963, foi uma disputa nada democrática, a campanha oposicionista era para desestruturar a presidência, começaram a anunciar: "A situação do país é grave" e concluíam, que era melhor os militares tutelá-lo (SCHWARCZ; STARLING, 2015. p. 443).

Jango não aprovou os idos de março e começa uma campanha anunciando suas reformas, que seriam elas: Agrária, de base, constituição de 46, o voto dos analfabetos. Para demonstrar sua determinação, Jango realizou em 13 de março, um discurso na Central do Brasil, ao estilo de Getulio Vargas, onde reuniu mais de 200 mil pessoas. Como resposta, a base oposicionista, 6 
dias após o discurso, realizou a Marcha da Família com Deus pela Liberdade com 500 mil pessoas, preparada pelo Ipes.

Segundo as pesquisadoras Schwarcz e Starling (2015, p. 444): [...] com a ausência de 29 parlamentares, em meio a protestos e aplausos, considerou vago o cargo de Presidente da República! Era mais uma violação à Constituição vigente, porque Jango ainda estava em território nacional!

E assim foi consumando o golpe. Segundo as autoras Schwarcz e Starling (2015, p. 447):

Ninguém imaginava outra coisa além de eleições em 1965. Mas todos estavam enganados. Uma facção entre golpistas tinha agenda própria, o governo dos militares iria durar 21 anos, e o Brasil acabava de ingressar numa longa ditadura.

O golpe é consumado, em 2 de abril de 1964, onde o presidente do senado convocou uma sessão secreta, decretando vaga a presidência do país3, mesmo como afirma, Aquino (2000, p. 672): Somente no dia 4 de abril, à tarde, Jango desembarcou no Uruguai, onde ficou asilado.

Contudo, a intervenção histórica militar, não se trata da mesma ordem do Exército, mas o jogo de interesse e a disputa pelo poder se mantiveram, lembrando que somente a partir da República, as forças armadas ganham vez e voz (GERMANO, 2011). Em 64, os militares consolidam o golpe, em contraposição a Democracia Populista, uma vez instalados no poder, os militares implantam seu próprio regime, um regime extremamente autoritário.

Segundo Loewenstein (1983, p.72) o regime caracterizou-se pelo fato de o "poder não estar submetido a nenhum limite, estar fora de qualquer controle político" em outras palavras, pós implantação, o acesso de lideranças políticas foi suspenso, já o poder legislativo, bem como o judiciário, passaram a ter papel simbólico, atuando conforme a vontade única e exclusiva do executivo, que impôs sua "soberania" através dos Atos Institucionais, ao longo dos 21 anos de ditadura militar no Brasil, 17 Atos Institucionais foram decretados.

A sucessão quase imperial da ditadura deu ao ministro da fazenda, poderes ilimitados como relembra o ex-ministro Maílson da Nóbrega (CARIELLO, 2014 apud SCHWARCZ; STARLING, 2015. p. 451), "Poderes de matar de inveja um rei medieval". O governo "provisório" militar iniciou quase 
que de imediato seu controle. Na noite de 9 de abril foi divulgado o documento conhecido como Ato Institucional $n^{\circ}$ 1. A partir de então iniciou-se o processo de "montagem", como refere-se Germano (2011), institucional da ditadura. O regime militar contou com 5 sucessões quase que imperiais, de generais na Presidência da República.

\title{
POLÍTICAS EDUCACIONAIS DOS ANOS DE CHUMBO
}

"A escolarização e qualificação da força de trabalho dizem respeito a uma das funções primordiais do Estado capitalista" (ALTVATER, 1977, OFFE e LENHARDT, 1984 apud GERMANO, 2011). Assim, poderemos constatar o grau de importância atribuído pelo regime militar, a educação no país.

As ações do comando militar, no campo da educação, apresentaram-se como prioridade, pois o regime tinha pressa na execução de seus planos. "Consumado o golpe militar, o IPES se dedicou a organizar um simpósio sobre a reforma da educação. Preparado nos meses de agosto a novembro, o simpósio se realizou em dezembro de 1964" (SAVIANI, 2008). Tal evento tinha por objetivo assegurar através da educação, o aumento da produtividade e da renda do país. Diante desta ambiciosa meta, a educação primária deveria capacitar para a realização de determinada atividade prática. Já o ensino médio teria como objetivo a preparação dos profissionais necessários ao desenvolvimento econômico e social do país. Ao ensino superior eram atribuídas as funções de formar a mão-de-obra especializada requerida pelas empresas e preparar os novos dirigentes do país (Souza, 1981, p. 67-68).

Segundo Demerval Saviani (2008):

\begin{abstract}
A orientação geral traduzida nos objetivos indicados e a referência a aspectos específicos, como a profissionalização do nível médio, a integração dos cursos superiores de formação tecnológica com as empresas e a precedência do Ministério do Planejamento sobre o da Educação na planificação educacional, são elementos que integrarão as reformas de ensino do governo militar.
\end{abstract}

As reformas do regime iniciaram "de cima para baixo", ou seja, pelo ensino superior, ou ainda como diria José Willington Germano (2011, p.104) 
"manobra pelo alto", através da lei $n^{\circ} 5.5 .40$ de 28 de novembro de 1968, regulamentada pelo Decreto no 464/69 que modificou a estrutura do ensino superior. Porém este decreto trata não apenas da reforma do sistema educacional, mas implicou a incorporação de duas dimensões essenciais para a dominação política existente: Restauração e, ao mesmo tempo, Renovação (GRAMSCI, 1977). Restauração, porque ao se revestir de legalidade, possibilitou o completo aniquilamento, por parte do Estado de Segurança Nacional, do movimento social e político dos estudantes e de outros setores da sociedade civil (GERMANO, 2011, p. 133).

A reforma do Ensino Primário começou alguns anos depois em 1971. Agindo desta forma fragmentada uma "revolução passiva" vai acontecendo sem a participação da sociedade civil, com intuito de, como salienta Evaldo Vieira (1984, p.47) desmoralizar "eventuais movimentos neste campo". Mas o governo logo começa encontrar obstáculos como a escassez de verba para a educação pública. (GERMANO, 2011, P.104).

É notório que o poder dos militares implantou um sistema de ensino que rompia com a singularidade regional, bem como os projetos populares de educação como os liderados por Paulo Freire, dando inicio a desaceleração da escola pública, em favorecimento do setor privado. (GERMANO, 2000, p.695). Prova deste feito é o Acordo MEC/USAID, em 68, no governo do General Costa e Silva, que resulta numa política educacional privatista com objetivo de tornar a educação utilitarista, Germano (2000) nos lembra que o acordo "definia o papel da educação como o de formador de mão-de-obra qualificada para gerenciamento da produção industrial - daí a explosão de curso universitário ligados ao saber tecnológico".

O governo militar implanta taxas e anuidade as universidades públicas, como se não bastasse, em 28 de fevereiro de 1969 promulga o Decreto ํo 477 que punia manifestações de professores, estudantes e funcionários das universidades. O esvaziamento da escola pública a desqualificação do professor marcam este período. A própria universidade sofreu com o regime, pois os militares implantaram a Operação Limpeza que tinha poder de expulsar e cassar professores e alunos que apresentassem com visão critica contraria as ações do regime militar. Em contrapartida o governo militar incentivava o desenvolvimento nas áreas de pesquisas tecnológicas, 
pois estava nos planos a modernização da economia e o domínio tecnológico (GERMANO, 2000, p. 696).

A atuação do Regime Militar manifesta-se segundo seu interesse de repressão e controle ideológico político do ensino, com objetivo de eliminar toda e qualquer forma de critica para consolidar seu projeto de dominação. $O$ terrorismo cultural também esta nos planos dos militares, tanto que nas palavras do Coronel Darcy Lázaro a respeito dos movimentos culturais, deixa clara a posição de governo em relação a tal tema: "Se esta história de cultura vai-nos atrapalhar a endireitar o Brasil, vamos acabar com a cultura durante trinta anos" (GERMANO, 2011, p. 105).

De acordo com José Willington Germano (2011, p. 106):

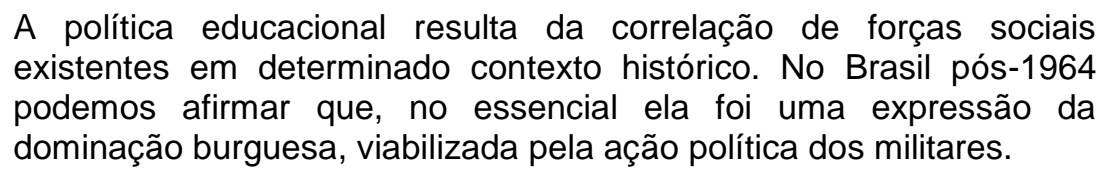

Deste modo o regime incentiva a participação do privado na expansão do próprio sistema educacional e desqualifica a escola pública. Num apanhado geral as reformas educacionais do período militar, concentraram-se de forma sintética nas seguintes ações: Reforma Universitária, acordo MEC/USAID, unificação da Escola primário/ginásio, implantação da disciplina Educação Moral e Cívica, eliminação de disciplina de filosofia e sociologia, implantação da língua inglesa, ensino obrigatório de 7 a 14 anos, ensino profissionalizante, rompimento com Educação Popular, exilando Paulo Freire, no Chile, instalação a educação tecnicista: com objetivo a neutralidade científica, inspirada nos princípios de racionalidade, eficiência e produtividade. O sistema de gestão no Brasil estava em adaptação do ensino, agora, voltado a uma mentalidade empresarial tecnocrata (SAVIANI, p.381, 2010).

\section{CONSIDERAÇÕES FINAIS}

Ao realizarmos o estudo referente à consolidação do golpe militar, a era ditatorial e quanto às políticas educacionais no Brasil, algumas considerações são inevitáveis, como por exemplo, ter claro os motivos que 
consolidam a implantação da ditadura, o cenário do país por duas décadas, que segundo Ghiraldelli, 1990, p.163, "serviram de palco para o revezamento de cinco generais na Presidência" e como estes governos mantiveram-se a frente do país.

Sob a justificativa da segurança do país, a disputa de poder vem a 5 séculos fazendo parte da nossa história, intensificando-se, a partir de 64 sobre toda forma de repressão, censura e violência, desde as mais sutis, as mais perversas, com bandeiras de ordem, de Brasil-Grande, o comando do país segue atendendo o interesse de uma elite, agora militar.

No campo Educacional o regime tratou a educação como uma instrumentalização necessária para 0 desenvolvimento do mercado de trabalho, era através das reformas educacionais que o regime atingiria seus objetivos, ampliando a economia através da qualificação da mão-de-obra, sem preocupação alguma com a formação integral do povo. Ainda como se não bastasse a educação também era tida como aparelho ideológico, ou melhor, de controle ideológico, em especial após o Al -15 de 69 com a Lei da Segurança Nacional com a pretensão de consenso e legitimação.

\section{REFERÊNCIAS}

AQUINO, Rubim Santos Leão de, Sociedade brasileira: uma história através dos movimentos sociais: da crise do escravismo ao apogeu do neoliberalismo $2^{\mathrm{a}}$ ed. - Rio de Janeiro: Record, 2000.

BRASIL, Atos Institucionais: Portal da Legislação: Governo Federal do Brasil, http://www4.planalto.gov.br/legislacao, visitado em 06, 07, 08 de janeiro de 2016.

GRAMSCI, Antonio. Os intelectuais e a organização da cultura. Rio de Janeiro, Civilização Brasileira, 1977.

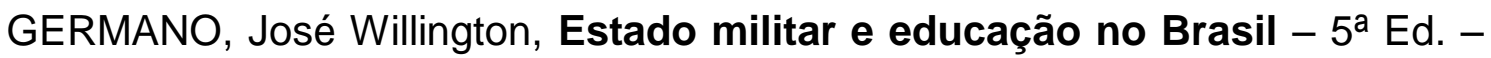
São Paulo: Cortez, 2011.

GONÇALVEZ, Nadia Gaiofatto, Fundamentos históricos e filosóficos da educação brasileira - Curitiba: Ibpex, 2005.

ROMANELLI, Otaíza de Oliveira, História da Educação no Brasil. Petrópolis:Vozes, 1978. 
SAVIANI, Demerval. História das ideias pedagógicas no Brasil. São Paulo, Autores Associados, 2007.

, Demerval, O legado educacional do século XX no Brasil - $2^{\mathrm{a}} \mathrm{Ed}$. Campinas, SP: Autores Associados, 2006. - (Coleção Educação Contemporânea)

O legado educacional do regime militar. Cad. Cedes, Campinas, vol. 28, n. 76, p. 291-312, set./dez. 2008 Disponível em http://www.cedes.unicamp.br

SOUZA, M.I.S. Os empresários e a educação: o IPES e a política educacional após 1964. Petrópolis: Vozes, 1981.

SCHWARCZ, Lilian Moritz; STARLING, Heloisa Murgel, Brasil: uma biografia 1를 Ed. - São Paulo: Companhia das Letras, 2015 